\title{
Working from Home in Developing Countries*
}

\author{
Charles Gottlieb, ${ }^{\dagger}$ Jan Grobovšek, ${ }^{\ddagger}$ Markus Poschke, ${ }^{\S}$ and Fernando Saltiel ${ }^{\uparrow}$
}

February 1, 2021

\begin{abstract}
We use worker-level data on the task content of jobs to measure the ability to work-fromhome (WFH) in developing countries. We show that the ability to WFH is low in developing countries and document significant heterogeneity across and within occupations, and across worker characteristics. Our measure suggests that educated workers, wage employees and women have a higher ability to WFH. Using data from Brazil, Costa Rica and Peru, we show that our measure is predictive of actual WFH both in terms of overall levels and variation with occupation and individual characteristics, as well as employment outcomes. Our measure can thus be used to predict WFH outcomes in developing countries.
\end{abstract}

Keywords: COVID-19, Occupations, Tasks, Work from home, Remote work.

\footnotetext{
* This work was supported by Leverhulme; the GFF Fund of the University of St. Gallen; ESRC-DFID [grant number ES/L012499/1]; the Social Sciences and Humanities Research Council [grant number 435-2018-0264] and McGill University. This paper supersedes "Working from home across countries" (Gottlieb, Grobovšek, and Poschke, 2020) and "Who can work from home in developing countries" (Saltiel, 2020). We thank seminar participants at the World Bank, DENS Conference at the University of St. Gallen and the Jobs and Development Conference for helpful comments and suggestions.

${ }^{\dagger}$ University of St. Gallen. Email: charles.gottlieb@unisg.ch

${ }^{\ddagger}$ University of Edinburgh. Email: jan.grobovsek@ed.ac.uk

$\S$ McGill University. Email: markus.poschke@mcgill.ca

๑McGill University. Email: fernando.saltiel@mcgill.ca
} 


\section{Introduction}

The spread of Covid-19 has led to the widespread adoption of social distancing in countries across the world, be it in response to government mandates or on a voluntary basis. Since social distancing frequently involves the closure of workplaces to limit interpersonal contact, the ability to work from home (WFH) is a key factor for determining the economic consequences of social distancing. Various papers have measured the ability to WFH in developed countries (Dingel and Neiman, 2020; Adams-Prassl et al., 2020a,b; Bick et al., 2020; Boeri et al., 2020; del Rio-Chanona et al., 2020; Fadinger et al., 2020; Alipour et al., 2020; Hensvik et al., 2020; Mongey et al., 2020), finding that around $40 \%$ of jobs could potentially be carried out from home. However, these measures cannot be directly extrapolated to developing countries, as the task content of occupations may vary significantly across contexts (Dicarlo et al., 2016; Lo Bello et al., 2019). Yet, understanding the ability to WFH of the workforce in these countries is of critical importance, as low-income countries also see extensive adoption of social distancing. ${ }^{1}$

In this paper, we measure the ability to work from home in developing countries, and also present evidence on who actually worked from home during the pandemic. We first take advantage of worker-level data on task content from the Skills Toward Employability and Productivity (STEP) survey, which covers 17,000 workers in urban areas across ten low- and middle-income countries. We follow Dingel and Neiman (2020) and build a measure of the ability to WFH in developing countries based on a task-exclusion approach. STEP includes detailed information on workers' occupations, self-employment status, educational attainment and gender. Since task content is measured at the worker-level in STEP, we can examine variation in workers' ability to work from home both across occupations and across demographic groups. Second, we rely on labor force surveys conducted in Brazil and Costa Rica during the pandemic, which measured actual work from home in the second quarter of 2020. Since these data sources include detailed information on workers' employment outcomes along with their observed characteristics, we again document heterogeneity in actual WFH across occupations as well as education and gender groups. Predicted WFH patterns computed using worker characteristics and our measure of the ability to WFH based on STEP data closely proxy actual WFH patterns in these countries.

Our WFH measure rules out working from home if a worker's job involves tasks that arguably make it impossible to exercise the job from home. These job tasks include repairing electronic equipment, operating heavy machinery, reporting that customer interaction is very important, reporting a physically demanding job or not using e-mail at work. According to this measure, only 9.3\% of workers in the full STEP sample can work from home. While this estimated aggregate WFH share is relatively low, there is substantial heterogeneity across occupations, as the estimated share of workers in elementary jobs who can WFH equals $1.3 \%$, while it reaches $23.8 \%$ for managers. We also find differences in WFH ability across workers' observed characteristics, as more educated

\footnotetext{
${ }^{1}$ Twenty-two low- and lower-middle income countries have implemented lockdowns with a stringency index above 80 (corresponding to the 75 th percentile of the world distribution) (Hale et al., 2020). Reductions in mobility are also similar in many countries; e.g. Figure A1 shows similar patterns in Brazil, Costa Rica, and the United States.
} 
workers, wage employees, females, and wealthier workers are more likely to be able to work from home, even within three-digit occupations. A variance decomposition exercise shows that the contribution of country fixed effects to the variance of predicted WFH is minor, indicating that our measure can be extrapolated to countries within the income range covered by STEP countries. Finally, the ability to WFH implied by STEP data is lower than that found in O*NET data from the US in almost all occupations. ${ }^{2}$

We examine the determinants of actual WFH during the pandemic using labor force surveys conducted in Brazil and Costa Rica in the second quarter of 2020. In Brazil, we observe whether individuals are working from home during the pandemic, and the Costa Rica survey captures whether individuals are teleworking. ${ }^{3}$ The estimated share of workers who are actually working from home equals just 10.6\% in Costa Rica and 13.3\% in Brazil, far below the corresponding shares in developed countries. These averages hide important differences in the likelihood of working from home across occupations, as the estimated WFH share for plant operators is below $1 \%$ in both countries, while it exceeds $40 \%$ for professionals. ${ }^{4}$ We further find that more educated workers, women, and wage employees are more likely to have worked from home during the pandemic, in line with our measure of WFH ability.

To validate our WFH ability measure, we impute a predicted WFH score for each worker in the Brazil and Costa Rica surveys based on their occupations and observed characteristics and our estimates from STEP. We document a strong association between predicted and observed WFH in these two countries. This gives us confidence in the transferability of our WFH ability measure to other countries in the same broad income range.

Note that for out-of-sample predictions, a validated measure of WFH ability presents several advantages compared to measures of actual WFH. First, data on actual WFH is rarely available in micro data sources. Our measure of WFH ability, in contrast, is based on information from ten different countries, and can be used to predict WFH using widely available data on workers' observed characteristics. Second, actual WFH outcomes depend on the stringency of lockdowns and precautionary behavior by households. These are driven by contemporaneous Covid-19 infection rates, which vary widely across countries and over time, as well as by differences in local technological infrastructure. Our WFH ability measure does not suffer from these issues.

Lastly, we examine the relationship between workers' WFH ability and their employment outcomes during the pandemic. We take advantage of Peru's labor force survey, which follows a rotating panel design, allowing us to observe workers' labor market outcomes in 2020. For each worker, we rely on their observed characteristics and occupation in 2019, to impute a predicted WFH score. We show that a higher WFH score is strongly associated with the likelihood of remaining employed

\footnotetext{
${ }^{2}$ Since our WFH measure relies on task questions which are also available in O*NET, we can compute an alternative, O*NET-based measure of WFH. Across almost all three-digit occupations, the O*NET-based measure predicts substantially higher WFH than our STEP-based measure. This result can be explained by differential task content within occupations in developed vis-à-vis developing countries (Lewandowski et al., 2019).

${ }^{3}$ For comparability with STEP, we focus on urban respondents in both countries.

${ }^{4}$ In Costa Rica, the estimated prevalence of WFH at the three-digit occupation level is strikingly similar to our predicted shares using STEP data.
} 
through 2020 in Peru, particularly in non-essential sectors. All in all, our WFH measure predicts actual WFH as well as employment outcomes in developing countries during the pandemic.

This paper makes several contributions to the nascent literature on workers' ability to work from home. It extends Saltiel (2020), who was the first to present evidence on the determinants of WFH in developing countries. ${ }^{5}$ It fits closely with a number of papers measuring the feasibility of working from home in developed economies (Dingel and Neiman, 2020; Adams-Prassl et al., 2020a,b; Bick et al., 2020; Boeri et al., 2020; del Rio-Chanona et al., 2020; Fadinger et al., 2020; Alipour et al., 2020; Hensvik et al., 2020; Mongey et al., 2020). As in Adams-Prassl et al. (2020b), our analysis goes beyond heterogeneity across occupations, as we document the importance of withinoccupation heterogeneity in workers' abilities to work from home. The paper thus also contributes to a broader literature examining within-occupation differences in task content (Autor and Handel, 2013; Stinebrickner et al., 2019).

To the best of our knowledge, ours is the first paper to examine patterns in actual work from home in developing countries. Importantly, this information allows us to validate our measure of WFH ability using information on workers' occupations and characteristics. Our validation extends Dingel and Neiman (2020) and Bick et al. (2020), who validated their measure of WFH ability using cross-country and industry-level variation on actual WFH, respectively.

The rest of the paper proceeds as follows. In Section 2, we present our worker-level measure of the ability to WFH in developing countries and examine heterogeneity across occupations and observed characteristics. In Section 3, we present evidence on the prevalence of actual WFH in Brazil and Costa Rica. We compare our WFH ability measure to workers' actual likelihood of working from home in these two countries. In Section 4, we take advantage of panel data from Peru to examine the relationship between WFH ability and actual employment outcomes during the Covid-19 pandemic. In Section 5, we discuss the results and conclude.

\section{Who Can Work from Home in Developing Countries?}

\subsection{Data Sources}

To measure the feasibility of working from home, we use data from the first two rounds of the STEP household survey, covering workers in urban areas across ten countries in 2012-2013, including Armenia, Bolivia, China (Yunnan Province), Colombia, Georgia, Ghana, Kenya, Laos, Macedonia and Vietnam. STEP surveys are representative of the working age (15-64 year old) population in urban areas across these countries. We use data on the main respondent, for whom we observe age, gender and educational attainment, along with information on labor market outcomes, including current employment status and whether they have worked in the past twelve months. ${ }^{6}$ Furthermore,

\footnotetext{
${ }^{5}$ Hatayama et al. (2020) and Garrote Sanchez et al. (2020) have more recently provided related evidence on this issue. However, the data they use do not allow measuring actual work from home.

${ }^{6}$ Since STEP also includes information on household assets, we classify respondents by their quintile ranking in the within-country asset index distribution as a measure of their capacity to cope with the shock.
} 
we observe whether they work as wage employees, in self-employment or in unpaid family work. ${ }^{7}$ STEP also includes workers' occupations under the harmonized ISCO-08 classification. We outline our data construction procedure and discuss how the various restrictions affect the final sample in Appendix B.

Finally, STEP also contains information on the tasks that respondents perform at work. Since all STEP country surveys include the same task content questions, the analysis is directly comparable across countries. Moreover, since information on tasks is gathered at the worker level, we can examine how workers' ability to work from home varies not just with occupation, but also with other individual characteristics.

\subsection{Work from Home Definition}

Our approach to measuring the feasibility of working from home follows Dingel and Neiman (2020) in aiming to capture whether workers could potentially work from home, and not whether they have done so in the past. ${ }^{8}$ STEP data allow us to construct a WFH ability measure across a wide range of countries by leveraging comparable worker-level data on job task content. We consider task measures which are informative of the physical and social nature of the job, along with information on technology use which may be carried out from home. Our definition rules out working from home if a worker performs any of the following tasks at work: repairing/maintaining electronic equipment, operating heavy machinery or industrial equipment, reporting they have a physically demanding job, reporting that contact with customers is very important, or not using e-mail at work. Table B1 in the Data Appendix reports our exact coding conventions.

\subsection{Empirical Evidence}

In the first column of Table 1, we present average WFH feasibility in the STEP sample. We include sample weights to represent the working-age population of 15-64 year olds in each country, and all countries are weighted equally. Overall, $9.3 \%$ of urban employment could be done remotely in the ten STEP countries. ${ }^{9,10}$ The ability to WFH varies strongly across broad occupation groups. While close to one-quarter of jobs in managerial, professional occupations and clerical support occupations could be done from home, fewer than $3 \%$ of jobs in elementary occupations, crafts, or occupations involving plant or machine operation can be done remotely. In Table A1, we show that similar results emerge in ability to WFH across the ten countries in the sample.

\footnotetext{
${ }^{7}$ We restrict the analysis to respondents who have been employed in the past twelve months. We further drop individuals in unpaid family work or in the armed forces.

${ }^{8}$ STEP does not include questions asking respondents whether they have previously worked from home.

${ }^{9}$ Internet access has grown significantly in developing countries since STEP surveys were carried out in 201213 (https://data.worldbank.org/indicator/IT.NET.USER.ZS). By ruling out WFH for workers who do not use e-mail, we may thus be underestimating the share of WFH in these countries. We address this concern by replacing the e-mail exclusion with a 'computer-use-at-work' exclusion, which captures jobs which required computers back in 2012-13 but may have incorporated e-mail use since. This alternative measure indicates that $12.9 \%$ of jobs in STEP could be done from home, remaining far below the developed country shares.

${ }^{10} \mathrm{STEP}$ contains information on urban residents. WFH ability in rural areas depends critically on the ability to WFH in the agricultural sector. See Gottlieb et al. (2021) for a discussion.
} 
The ability to WFH varies not only at the occupation level, but also across personal and job characteristics. In the second and third columns of Table 1, we show that educational attainment is a strong predictor of the ability to work from home, as the estimated share for high school completers surpasses that of dropouts by 13 percentage points. High school graduates have higher WFH ability than their dropout counterparts across all occupations, and these differences are significant across all but two broad occupation groups. Similarly, the ability to WFH for wage employees $(12.4 \%)$ is far higher than for self-employed workers $(3.3 \%) .{ }^{11,12}$

Table 1: WFH ability by Occupations and Characteristics in STEP

\begin{tabular}{|c|c|c|c|c|c|c|c|}
\hline \multirow[b]{2}{*}{ One-Digit Occupation } & \multirow[b]{2}{*}{$\begin{array}{c}\text { Full Sample } \\
\text { (1) }\end{array}$} & \multicolumn{2}{|c|}{ Educational Attainment } & \multicolumn{2}{|c|}{ Self-Employment } & \multicolumn{2}{|c|}{ Gender } \\
\hline & & $\begin{array}{c}\text { HS Graduate } \\
(2)\end{array}$ & $\begin{array}{l}\text { HS Dropout } \\
(3)\end{array}$ & $\begin{array}{l}\text { Wage Employee } \\
(4)\end{array}$ & $\begin{array}{c}\text { Self-Employed } \\
(5)\end{array}$ & $\begin{array}{l}\text { Female } \\
(6)\end{array}$ & $\begin{array}{c}\text { Male } \\
(7)\end{array}$ \\
\hline Managers & 0.238 & 0.258 & $0.084^{* * *}$ & 0.301 & $0.160^{* * *}$ & 0.233 & 0.242 \\
\hline Professionals & 0.196 & 0.202 & $0.099^{* * *}$ & 0.201 & $0.154^{*}$ & 0.193 & 0.203 \\
\hline Technicians and Associate Professionals & 0.200 & 0.222 & $0.082^{* * *}$ & 0.214 & $0.101^{* * *}$ & 0.215 & 0.186 \\
\hline Clerical Support Workers & 0.282 & 0.315 & $0.128^{* * *}$ & 0.286 & $0.176^{*}$ & 0.326 & $0.205^{* * *}$ \\
\hline Services and Sales Workers & 0.030 & 0.054 & $0.009^{* * *}$ & 0.045 & $0.017^{* * *}$ & 0.027 & 0.036 \\
\hline Skilled Agricultural, Forestry and Fishery Workers & 0.001 & 0.005 & 0.000 & 0.003 & 0.000 & 0.000 & 0.001 \\
\hline Craft and Related Trades Workers & 0.012 & 0.022 & $0.004^{* * *}$ & 0.011 & 0.012 & 0.010 & 0.013 \\
\hline Plant and Machine Operators, and Assemblers & 0.007 & 0.014 & 0.000 & 0.009 & 0.003 & 0.007 & 0.008 \\
\hline Elementary Occupations & 0.013 & 0.040 & $0.001^{* * *}$ & 0.014 & 0.011 & 0.018 & $0.008^{*}$ \\
\hline Sample Average & 0.093 & 0.148 & $0.014^{* * *}$ & 0.124 & $0.033^{* * *}$ & 0.100 & $0.084^{* * *}$ \\
\hline Observations & 17,592 & 10,090 & 7,502 & 11,095 & 6,497 & 9,349 & 8,243 \\
\hline
\end{tabular}

Source: Skills Toward Employability and Productivity (STEP) Survey. Note: Table 1 documents the share of workers who can work from home by one-digit occupation, educational attainment, self-employment and gender. Results are weighted using sample weights to represent the working-age population of 15-64 year olds in each STEP country. We estimate a test of equality of WFH means across educational attainment, self-employment and gender and present the relevant standard errors in columns $(3),(5)$ and $(7)$, respectively. ${ }^{*} p<0.10, * * p<0.05, * * *$ $p<0.01$.

These differences are particularly salient among individuals in high-paying managerial or professional occupations. In the first two panels of Figure 1, we show that wage employees and high school completers have high relative likelihoods of being able to work from home in all STEP countries. Lastly, women have a slightly higher ability to WFH than men, with significant differences emerging among managers, professionals, clerical support workers and services/sales workers.

In the last panel of Figure 1, we show heterogeneity in WFH ability across the within-country asset index distribution. The sample average shows that just $3.3 \%$ of households in the bottom quintile can work from home, while $17.3 \%$ of their wealthier peers in the top quintile can. As such, workers with limited access to self-insurance are far less likely to be able to work from home in developing countries. These results illustrate the importance of measuring task content at the worker-level (see also Adams-Prassl et al., 2020b). This is an important advantage of the STEP data, in contrast to e.g. $\mathrm{O}^{*} \mathrm{NET}$, which only allows for occupation-based measures - see section 2.5 for a further comparison to $\mathrm{O}^{*} \mathrm{NET}$.

The evidence presented so far shows that both occupations and workers' characteristics are important determinants of WFH ability. To further understand the contribution of different factors

\footnotetext{
${ }^{11}$ We also find large differences across workers' formal employment status, as $16.1 \%$ of formal workers are able to WFH, compared to just $4.7 \%$ of their informal counterparts.

${ }^{12}$ In Table A2, we document WFH ability across the joint distribution of workers' occupation, gender, education, and self-employment status.
} 
Figure 1: Ability to Work from Home by Observed Characteristics and Country

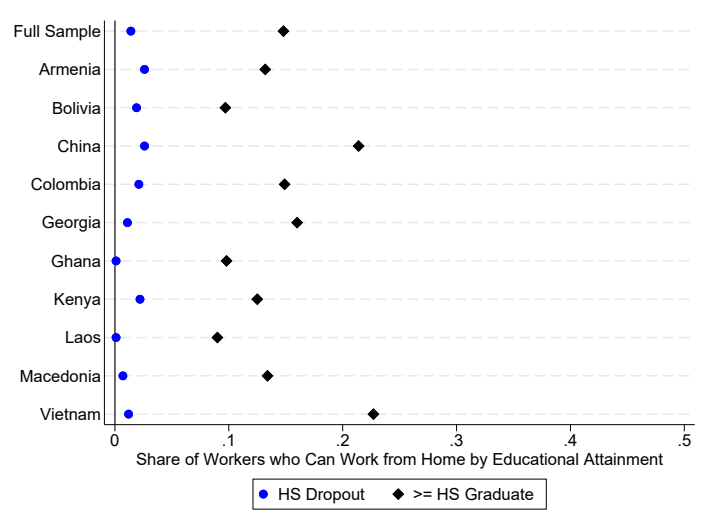

(a) By HS Dropout Status

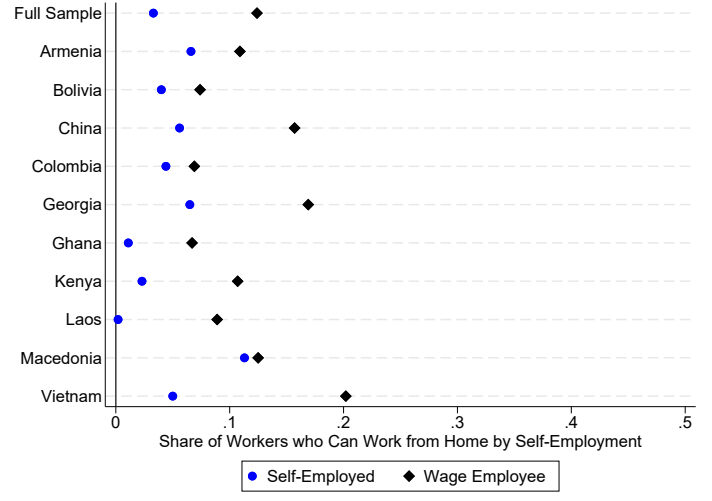

(b) By Self-Employment

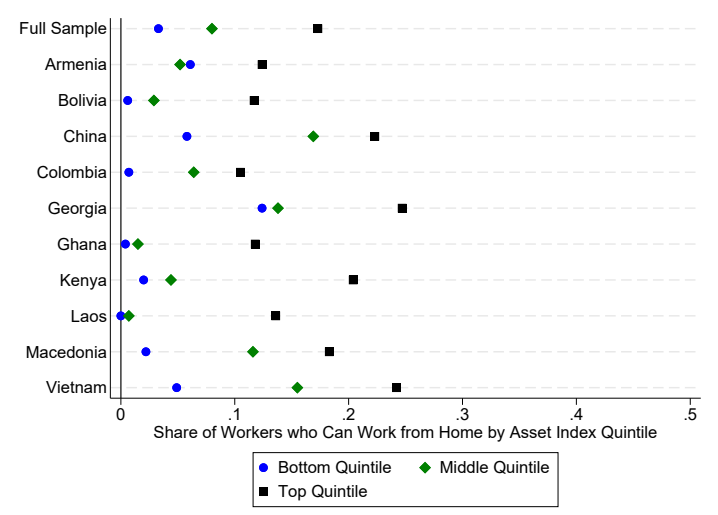

(c) By Asset-Index Quintile

Source: Skills Toward Employability and Productivity (STEP) Survey.

Note: Figure 1 presents the share of jobs which can be done from home in the full sample and across STEP countries by workers' high school dropout status (Panel A), self-employment status (Panel B), and asset index quintile (Panel C). Results are weighted using sample weights to represent the working-age population of 15-64 year olds.

to differences in the ability to work from home, we estimate the following regression:

$$
W F H_{i o c}=\beta \boldsymbol{X}_{i}+\gamma_{o}+\lambda_{c}+\varepsilon_{i o c}
$$

where $\boldsymbol{X}_{i}$ represents a vector of worker $i$ 's observed characteristics, including educational attainment (in years), age, gender and self-employment status; $\gamma_{o}$ captures one- or three-digit occupational fixed effects and $\lambda_{c}$ denotes country fixed effects. We present the estimated results of equation (1) in Table 2. The first column shows that higher-educated workers, wage employees and women are more likely to be able to work from home. In the second column, we control for one-digit occupations, finding that the sign of the estimated coefficients remains the same - with varying statistical significance, echoing the bivariate patterns reported in Table 1. Importantly, in the last column, we still find that workers' observed characteristics play an important role in driving the ability to WFH even within narrowly defined three-digit occupations. We thus remark the importance of 
using worker-level task content data for measuring the ability to work from home in developing countries.

Table 2: Determinants of WFH Ability: Observables and Occupations

\begin{tabular}{lccc}
\hline \hline & $(1)$ & $(2)$ & $(3)$ \\
\hline Educational Attainment & $0.015^{* * *}$ & $0.008^{* *}$ & $0.007^{* * *}$ \\
& $(0.003)$ & $(0.003)$ & $(0.002)$ \\
Age & 0.022 & 0.020 & 0.018 \\
& $(0.016)$ & $(0.013)$ & $(0.014)$ \\
Age $^{2}$ & -0.003 & -0.003 & -0.003 \\
& $(0.002)$ & $(0.002)$ & $(0.002)$ \\
Male & $-0.024^{*}$ & -0.015 & $-0.024^{*}$ \\
& $(0.011)$ & $(0.012)$ & $(0.012)$ \\
Wage Employment & $0.037^{* *}$ & 0.018 & $0.024^{* *}$ \\
& $(0.012)$ & $(0.010)$ & $(0.008)$ \\
\hline Observations & 17592 & 17592 & 17591 \\
$R^{2}$ & 0.083 & 0.138 & 0.203 \\
Occupation FE & None & One-Digit & Three-Digit \\
\hline \hline
\end{tabular}

Source: Skills Toward Employability and Productivity (STEP) Survey.

Note: Standard errors in parentheses. Table 2 presents the estimated coefficients from equation (1) across different specifications. The first column does not include occupation fixed effects, whereas the second and third columns include one- and three- digit occupation fixed effects, respectively. Results are weighted using sample weights to represent the working-age population of $15-64$ year olds in the sample. We normalize age by dividing it by ten. Robust standard errors in parentheses. ${ }^{*} p<0.10,{ }^{* *} p<0.05, * * * p<0.01$.

\subsection{Cross-Country Heterogeneity}

While we have so far focused on sample averages, STEP covers a wide range of countries across the development spectrum - their GDP per capita (PPP) ranges from $\$ 3,000$ to upwards of $\$ 14,000$. In Figure A2, we document important cross-country heterogeneity in WFH ability — ranging from $3.2 \%$ in Ghana to $15.4 \%$ in Georgia - which is strongly correlated with countries' income per capita. The income elasticity of the share of jobs which can be done from home equals 0.046.

To assess whether cross-country differences in the ability WFH can be explained by variation in countries' occupational structure and workers' observables, we conduct a variance decomposition exercise following the estimated coefficients from equation (1). We present the results in Table 3. Workers' characteristics on their own account for $2 \%$ of the variance in the WFH measure, along with an additional 3.7\% through the covariance with occupational categories. Occupations are strong drivers of the ability to WFH. One-digit groups account for $7.2 \%$ of the estimated variance, and this share increases to $14.2 \%$ at the three-digit level. The contribution of country fixed effects to the WFH variance is negligible (0.6-0.8\%), indicating that cross-country differences in WFH in the STEP sample are largely explained by differential employment structures in these countries.

Our estimates of WFH ability across occupations and workers' observed characteristics are therefore robust across a large spectrum of developing countries over the span covered by the STEP countries $(\$ 3,000-\$ 14,000)$. In particular, they can be used to compute WFH ability for 
Table 3: Variance Decomposition of WFH Ability

\begin{tabular}{lcc}
\hline \% Explained & $(1)$ & $(2)$ \\
\hline Variance & 1.000 & 1.000 \\
$\operatorname{Var}\left(X_{i}\right)$ & 0.022 & 0.018 \\
$\operatorname{Var}\left(\gamma_{O}\right)$ & 0.072 & 0.142 \\
$\operatorname{Var}\left(\lambda_{c}\right)$ & 0.008 & 0.006 \\
$\operatorname{Cov}\left(X_{i}, \gamma_{O}\right)$ & 0.038 & 0.037 \\
$\operatorname{Cov}\left(X_{i}, \lambda_{c}\right)$ & -0.001 & 0 \\
$\operatorname{Cov}\left(\gamma_{O}, \lambda_{c}\right)$ & -0.002 & 0 \\
$\operatorname{Var}\left(\varepsilon_{i o c}\right)$ & 0.862 & 0.797 \\
\hline$R^{2}$ & 0.137 & 0.202 \\
\hline Occ FE & One-Digit & Three-Digit \\
Observations & \multicolumn{2}{c}{17,592} \\
\hline \hline
\end{tabular}

Source: Skills Toward Employability and Productivity (STEP) Survey. Note: Table 3 presents a variance decomposition following equation (1). The 'Variance' row denotes the share of the variance in the WFH measure to be explained and all the rows below denote the share of the variance accounted by each variable. The first and second columns include one- and three- digit occupation fixed effects, respectively. Results are weighted using sample weights to represent the working-age population of 15-64 year olds in the sample.

other countries with available information on their employment composition.

\subsection{Comparison to Alternative Definitions}

Recent work has documented important cross-country differences in task content even in the same occupation (Lo Bello et al., 2019; Lewandowski et al., 2019; Saltiel, 2019): for instance, the tasks performed by a cashier in Spain can differ significantly from those done by her counterpart in Bolivia. As such, extrapolating WFH measures using task-content information from developed countries — such as the $\mathrm{O}^{*} \mathrm{NET}$ - will not accurately capture cross-country differences in tasks. This is also the case for the ability to work from home.

We illustrate this point by comparing the estimated share of jobs which can be done from home in an occupation according to our measure to an analogous measure based on $\mathrm{O}^{*} \mathrm{NET}$ data. To do so, we take advantage of task questions in $\mathrm{O}^{*} \mathrm{NET}$ that are analogous to the five task exclusions discussed in Section 2.2 to develop a directly comparable WFH measure. ${ }^{13}$

In Figure 2, we compare estimated WFH shares by occupation from STEP and from $\mathrm{O}^{*} \mathrm{NET}$. The STEP-based measure indicates lower estimated likelihood of WFH in $93 \%$ of three-digit occupations. ${ }^{14}$ This underlines the importance of using measures of WFH ability, measured in an appropriate context, for assessing the feasibility of WFH in developing countries.

\footnotetext{
${ }^{13}$ We present a direct crosswalk of task measures in the O*NET and STEP in Table B1. Note that differences in within-occupation WFH shares between STEP and O*NET are not driven by differential survey designs, as the task questions used to measure WFH in both surveys are answered by incumbent workers (Handel, 2016).

${ }^{14}$ In Figure A3, we provide a comparison to O*NET-based measure of Dingel and Neiman (2020). Their measure uses a larger number of exclusions relative to ours. This tends to reduce WFH measures. Still, the STEP-based measure predicts a lower WFH likelihood in $78 \%$ of three-digit occupations, further highlighting differences in task content across contexts. In Table A3, we list WFH shares for these two measures by two-digit occupations.
} 
Figure 2: Comparison of Predicted WFH Ability Across STEP and O*NET

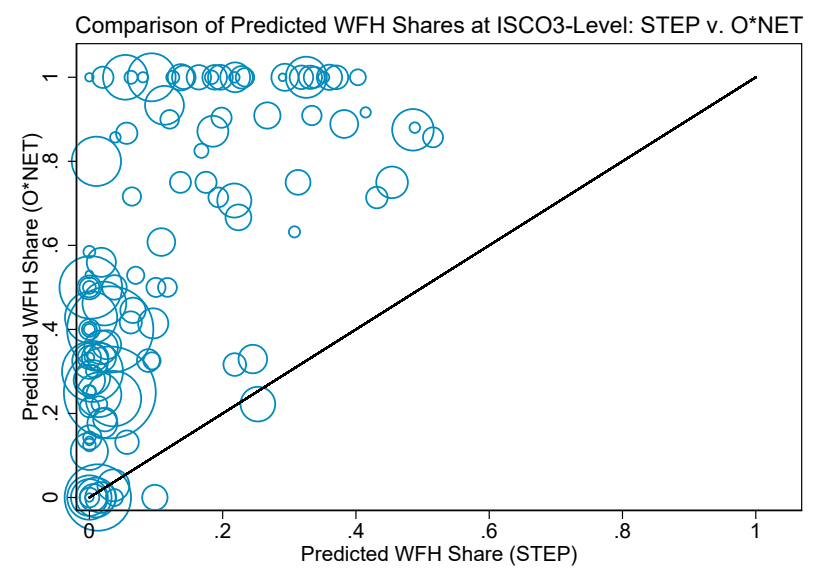

Source: Skills Toward Employability and Productivity (STEP) Survey and O*NET.

Note: Figure 2 presents the share of jobs which can be done from home at the three-digit occupation level following the measure introduced in Section 2.2. We compare the estimated WFH share to an O*NET-based equivalent measure to our WFH measure, as described in Section 2.5. We restrict the analysis to three-digit occupations with at least ten respondents in STEP. Results are weighted using STEP sample weights to represent the working-age population of 15-64 year olds.

\section{Who is Working from Home?}

In this section, we analyze the share of workers who actually worked from home during the second quarter of 2020 in Brazil and Costa Rica. ${ }^{15}$ While the extent of social distancing policies varied in these two countries, the stringency index measure presented in Hale et al. (2020) places both countries far above the worldwide median. In fact, in Figure A1, we show that workplace mobility in both countries fell significantly in the second quarter of 2020, closely resembling the mobility drop experienced in the United States.

\subsection{Data Sources}

Brazil. We use data from a nationally-representative survey of Brazilian households (PNAD COVID-19) carried out in May and June, 2020, which is an adaptation of Brazil's monthly household survey. PNAD COVID-19 interviewed Brazilian households remotely via telephone, covering questions related to health issues along with information on household members' employment outcomes. ${ }^{16}$ As such, we observe detailed information on workers' labor market outcomes during the pandemic, including whether they worked in the previous week, their wage/self-employment status and one-digit occupations. Additionally, respondents report their age, educational attainment and gender. Critical to our analysis, PNAD COVID-19 includes a measure of whether respondents started working from home during the pandemic.

\footnotetext{
${ }^{15}$ To the best of our knowledge, these are the only household surveys conducted during the first wave of the pandemic in developing countries which include information on whether individuals are working from home.

${ }^{16}$ The main sample covered 349,306 individuals, drawn from Brazil's continuous monthly household survey.
} 
Costa Rica. We use information from Costa Rica's quarterly labor force survey (ECE), which was carried out by phone in the second quarter of 2020. This survey included standard questions related to workers' labor market status, along with additional questions aimed at capturing outcomes during the pandemic. We observe whether respondents were employed in the previous week, their three-digit occupation and self-employment status, along with the same observed characteristics available in Brazil. Importantly, ECE includes a detailed question capturing workers' place of employment, which allows us to observe whether individuals 'teleworked' in the reference week. In light of the low prevalence of remote work in Latin America prior to Covid-19 (see Figure A4), the WFH measures available in Brazil and Costa Rica allow us to present initial evidence on the drivers of working from home in developing countries during the pandemic.

Sample Construction. For comparability with the STEP surveys, we restrict the sample to workers residing in urban areas across both countries. Moreover, we focus on prime-age workers (18-59 years old) who had worked in the week prior to the interview, and for whom we observe occupational information. Our sample covers 163,861 workers in Brazil and 3,221 in Costa Rica.

\subsection{Actual WFH Across Occupations and Characteristics}

In Table 4, we present evidence on the share of employment that is actually done remotely during the pandemic along with the types of individuals who are working from home. In the first panel, we show results for Brazil, where 13.3\% of urban workers started working from home during May and June, 2020. The estimated share of WFH is far below the corresponding share for European countries (Dingel and Neiman, 2020; Adams-Prassl et al., 2020b; Eurofound, 2020), which ranged from 20\% in Romania to upwards of $50 \%$ in Luxembourg. Nonetheless, there is substantial heterogeneity in the share of remote work across occupations, ranging from $23 \%$ for managers and $41 \%$ for professionals, while remaining at $1 \%$ for craft workers and machine operators. Differences in WFH associated with workers' observed characteristics fit in line with our predicted patterns, as the prevalence of WFH is far higher among high school completers, wage employees, and women. These differences remain significant within most broad occupational groups, albeit with varying statistical significance. For instance, the estimated share of managers with a high school degree who started working from home in the pandemic exceeds the corresponding share for HS dropouts by 20 percentage points.

In the second panel of Table 4, we present evidence for Costa Rica, where $10.8 \%$ of urban workers worked remotely in the second quarter of 2020. As in Brazil, we find significant differences in actual WFH across occupations - about half of professionals worked from home, compared to almost no workers in lower-paying occupations. Furthermore, we find similar patterns across workers' observed characteristics, which indicate that more wage employees, high school graduates and women actually worked from home.

To the best of our knowledge, our paper is the first to document the factors driving actual WFH in developing countries during the pandemic. Our results fit in with recent evidence across developed countries documenting a higher likelihood of remote work for more educated workers 
(Adams-Prassl et al., 2020b; Bick et al., 2020; Farr et al., 2020; Andrew et al., 2020; Alipour et al., 2020; Belot et al., 2020). Meanwhile, while women have borne a disproportionate share of employment losses in many countries, various papers have found that among those who work, actual WFH is more prevalent for women than for men. (Bick et al. (2020) present evidence on the U.S., Farr et al. (2020) on Spain, Andrew et al. (2020) on the UK.) ${ }^{17}$

Table 4: Actual Work from Home by Occupation and Characteristic

Panel A. Evidence from Brazil

\begin{tabular}{|c|c|c|c|c|c|c|c|}
\hline \multirow[b]{2}{*}{ One-Digit Occupation } & \multirow[b]{2}{*}{$\begin{array}{c}\text { Full Sample } \\
\text { (1) }\end{array}$} & \multicolumn{2}{|c|}{ Educational Attainment } & \multicolumn{2}{|c|}{ Self-Employment } & \multicolumn{2}{|c|}{ Gender } \\
\hline & & $\begin{array}{c}\text { HS Graduate } \\
(2)\end{array}$ & $\begin{array}{c}\text { HS Dropout } \\
(3)\end{array}$ & $\begin{array}{c}\text { Wage Employee } \\
(4)\end{array}$ & $\begin{array}{c}\text { Self-Employed } \\
(5)\end{array}$ & $\begin{array}{c}\text { Female } \\
(6)\end{array}$ & $\begin{array}{c}\text { Male } \\
(7)\end{array}$ \\
\hline Managers & 0.236 & 0.256 & $0.040^{* * *}$ & 0.264 & $0.225^{* *}$ & 0.265 & $0.218^{* * *}$ \\
\hline Professionals & 0.410 & 0.410 & 0.396 & 0.432 & $0.324^{* * *}$ & 0.412 & 0.406 \\
\hline Technicians and Associate Professionals & 0.220 & 0.220 & 0.000 & 0.232 & $0.149^{* * *}$ & 0.295 & $0.184^{* * *}$ \\
\hline Clerical Support Workers & 0.172 & 0.180 & $0.069^{* * *}$ & 0.172 & . & 0.171 & 0.174 \\
\hline Services and Sales Workers & 0.038 & 0.050 & $0.010^{* * *}$ & 0.042 & $0.028^{* * *}$ & 0.049 & $0.027 * * *$ \\
\hline Skilled Agricultural, Forestry and Fishery Workers & 0.007 & 0.018 & $0.001^{* * *}$ & 0.005 & 0.007 & 0.007 & 0.007 \\
\hline Craft and Related Trades Workers & 0.011 & 0.019 & $0.005^{* * *}$ & 0.007 & $0.014^{* * *}$ & 0.027 & $0.008^{* * *}$ \\
\hline Plant and Machine Operators, and Assemblers & 0.008 & 0.011 & $0.004^{* * *}$ & 0.008 & 0.008 & 0.012 & 0.008 \\
\hline Elementary Occupations & 0.042 & 0.073 & $0.010^{* * *}$ & 0.023 & $0.104^{* * *}$ & 0.031 & $0.065^{* * *}$ \\
\hline Sample Average & 0.133 & 0.182 & $0.011^{* * *}$ & 0.157 & $0.073^{* * *}$ & 0.178 & $0.098^{* * *}$ \\
\hline Observations & 163861 & 116911 & 46950 & 114455 & 41958 & 70887 & 92974 \\
\hline
\end{tabular}

Panel B. Evidence from Costa Rica

\begin{tabular}{|c|c|c|c|c|c|c|c|}
\hline \multirow[b]{2}{*}{ One-Digit Occupation } & \multirow[b]{2}{*}{$\begin{array}{c}\text { Full Sample } \\
\text { (1) }\end{array}$} & \multicolumn{2}{|c|}{ Educational Attainment } & \multicolumn{2}{|c|}{ Self-Employment } & \multicolumn{2}{|c|}{ Gender } \\
\hline & & $\begin{array}{c}\text { HS Graduate } \\
(2)\end{array}$ & $\begin{array}{l}\text { HS Dropout } \\
\text { (3) }\end{array}$ & $\begin{array}{l}\text { Wage Employee } \\
\text { (4) }\end{array}$ & $\begin{array}{c}\text { Self-Employed } \\
(5)\end{array}$ & $\begin{array}{c}\text { Female } \\
(6)\end{array}$ & $\begin{array}{l}\text { Male } \\
(7)\end{array}$ \\
\hline Managers & 0.208 & 0.208 & . & 0.217 & . & 0.385 & 0.000 \\
\hline Professionals & 0.520 & 0.520 & . & 0.569 & $0.063^{* * *}$ & 0.526 & 0.510 \\
\hline Technicians and Associate Professionals & 0.192 & 0.207 & $0.111^{*}$ & 0.213 & $0.042^{* * *}$ & 0.252 & $0.158^{*}$ \\
\hline Clerical Support Workers & 0.243 & 0.272 & $0.073^{* * *}$ & 0.246 & . & 0.252 & 0.233 \\
\hline Services and Sales Workers & 0.004 & 0.008 & 0.000 & 0.004 & 0.006 & 0.005 & 0.003 \\
\hline Skilled Agricultural, Forestry and Fishery Workers & 0.000 & 0.000 & 0.000 & 0.000 & 0.000 & 0.000 & 0.000 \\
\hline Craft and Related Trades Workers & 0.002 & 0.007 & 0.000 & 0.005 & 0.000 & 0.011 & 0.000 \\
\hline Plant and Machine Operators, and Assemblers & 0.000 & 0.000 & 0.000 & 0.000 & 0.000 & 0.000 & 0.000 \\
\hline Elementary Occupations & 0.000 & 0.000 & 0.000 & 0.000 & 0.000 & 0.000 & 0.000 \\
\hline Sample Average & 0.108 & 0.203 & $0.005^{* * *}$ & 0.137 & $0.007^{* * *}$ & 0.162 & $0.071^{* * *}$ \\
\hline Observations & 3221 & 1682 & 1539 & 2512 & 593 & 1314 & 1907 \\
\hline
\end{tabular}

Source: PNAD-COVID19 (Brazil) and Encuesta Continua de Empleo (ECE, Costa Rica). Note: Table 4 documents the share of workers who are working from home in Brazil and Costa Rica by one-digit occupation, educational attainment, self-employment and gender. Standard errors in parentheses. $* p<0.10, * * p<0.05, * * * p<0.01$.

The results presented so far for Brazil and Costa Rica match our STEP-based ability to WFH measure, as workers' characteristics relate to the likelihood of having worked from home within broad occupational groups in a similar way as they do for the ability to WFH analyzed in the previous section. To assess the relative contribution of workers' characteristics and occupations to actual WFH, we estimate equation (1) in these two countries and present the results in Table 5. This shows that the estimated patterns documented above are robust to controlling for occupation. Importantly, more educated workers and wage employees are more likely to have worked from home

\footnotetext{
${ }^{17}$ Adams-Prassl et al. (2020b) find that women report being able to do a smaller share of their job tasks from home. This measure differs from the binary measure of actual WFH considered in our paper and in Bick et al. (2020); Farr et al. (2020); Andrew et al. (2020).
} 
even within narrowly-defined three-digit occupations in Costa Rica. This again illustrates that the work from home propensity varies not just across occupations, but that there also is significant heterogeneity within occupations.

Table 5: Determinants of Observed WFH in Brazil and Costa Rica

\begin{tabular}{lccccc}
\hline \hline & \multicolumn{3}{c}{ Brazil } & \multicolumn{3}{c}{ Costa Rica } \\
& $(1)$ & $(2)$ & $(3)$ & $(4)$ & $(5)$ \\
\hline Educational Attainment & $0.028^{* * *}$ & $0.013^{* * *}$ & $0.030^{* * *}$ & $0.005^{* * *}$ & $0.003^{* *}$ \\
& $(0.000)$ & $(0.000)$ & $(0.002)$ & $(0.002)$ & $(0.001)$ \\
Age & $0.041^{* * *}$ & $0.012^{* *}$ & $0.083^{* *}$ & -0.008 & -0.001 \\
& $(0.005)$ & $(0.005)$ & $(0.032)$ & $(0.030)$ & $(0.027)$ \\
Age $^{2}$ & $-0.002^{* * *}$ & 0.000 & $-0.009^{* *}$ & 0.001 & -0.001 \\
& $(0.001)$ & $(0.001)$ & $(0.004)$ & $(0.004)$ & $(0.003)$ \\
Male & $-0.033^{* * *}$ & $-0.004^{* *}$ & $-0.030^{* * *}$ & -0.018 & -0.010 \\
& $(0.002)$ & $(0.002)$ & $(0.011)$ & $(0.011)$ & $(0.014)$ \\
Wage Employment & $0.037^{* * *}$ & $0.013^{* * *}$ & $0.076^{* * *}$ & $0.045^{* * *}$ & $0.016^{* *}$ \\
& $(0.002)$ & $(0.002)$ & $(0.007)$ & $(0.008)$ & $(0.008)$ \\
\hline Observations & 156413 & 133227 & 3104 & 3104 & 3104 \\
$R^{2}$ & 0.141 & 0.228 & 0.203 & 0.342 & 0.534 \\
Occupation FE & None & One-Digit & None & One-Digit & Three-Digit \\
\hline \hline
\end{tabular}

Source: PNAD-COVID19 (Brazil) and Encuesta Continua de Empleo (ECE, Costa Rica). Table 5 presents the estimated coefficients from equation (1) across different specifications using employment outcomes in Brazil and Costa Rica in the second quarter of 2020. The first and third columns do not include occupation fixed effects, whereas the second and fourth columns include one-digit occupation fixed effects, respectively. The last column incorporates three-digit occupation fixed effects in Costa Rica. We normalize age by dividing it by ten. Robust standard errors in parentheses. ${ }^{*} p<0.10,{ }^{* *} p<0.05, * * * p<0.01$.

\subsection{Comparing Predicted and Actual WFH}

Next, we compare actual WFH outcomes in Brazil and Costa Rica to our STEP-based measures of the ability to WFH. We first validate our measure at the occupational level, comparing predicted WFH across occupations to the share of telework in these jobs in Costa Rica. ${ }^{18}$ Figure 3 shows that across both two- and three-digit occupations, our measure is a strong predictor of the prevalence of WFH, as the majority of occupational averages lie close to the 45 degree line. For instance, our measure predicts that $16.4 \%$ of the three-digit occupation "Sales Agents and Brokers" could work from home, and $15.5 \%$ of them in fact teleworked in Costa Rica during the second quarter of 2020.

At the same time, our preferred measure additionally considers workers' characteristics in predicting their ability to work from home. We thus present evidence from an empirical exercise which leverages differential WFH ability across occupations and observed characteristics. In particular, in the STEP sample, we estimate a probit of the predicted likelihood of WFH including workers' characteristics and their one-digit occupation. We then use the estimated coefficients from the regression to impute a STEP-predicted WFH likelihood for each worker in the Brazil and Costa Rican samples. We subsequently compare the STEP-predicted work from home probability against workers' actual WFH outcomes during the pandemic in these two countries in a binned scatter plot. In each country, we divide the predicted probabilities in twenty equal-sized groups and compare

\footnotetext{
${ }^{18}$ This exercise cannot be done for Brazil, as we do not observe detailed occupational codes there.
} 
them to the share of workers in the bin who are actually working from home.

Figure 3: Comparison of Predicted and Observed WFH in Costa Rica, by Occupations

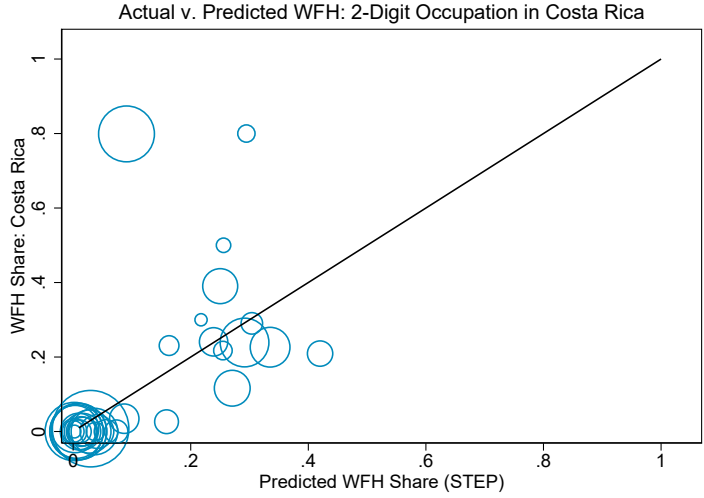

(a) Two-Digit Occupation

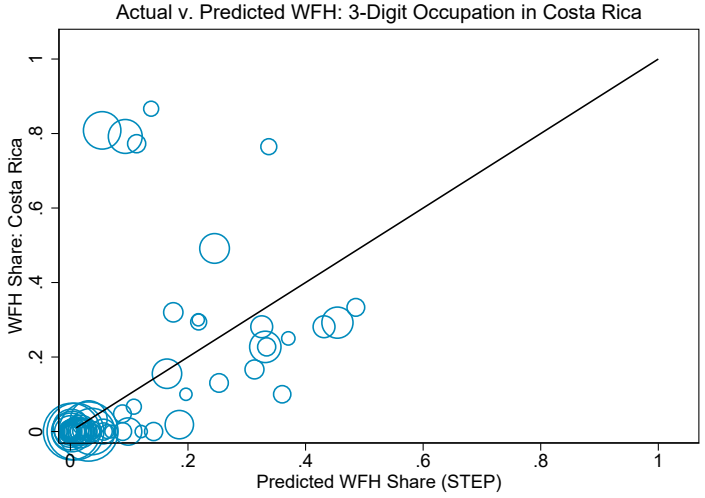

(b) Three-Digit Occupation

Source: Skills Toward Employability and Productivity (STEP) Survey and Encuesta Continua de Empleo (ECE in Costa Rica).

Note: Figure 3 presents the share of jobs which can be done from home at the two and three-digit occupation level following the measure introduced in Section 2.2. We compare the estimated WFH share to the share of jobs being done from home across two- and three-digit occupations in Costa Rica in the second quarter of 2020. We restrict the analysis to occupations with at least ten respondents in both STEP and ECE. Results are weighted using STEP sample weights to represent the working-age population of 15-64 year olds in STEP.

We present the results in Figure 4. In Brazil, the estimated share of individuals who worked from home in the second quarter of 2020 rises along with their predicted WFH probabilities from the STEP sample. In Costa Rica, meanwhile, a substantial share of workers did not telework during the pandemic. For these workers, we had predicted WFH probabilities below $3 \%$. Similar to Brazil, we predict a higher likelihood of being able to work from home for workers who were more likely to have actually teleworked in Costa Rica.

We extend this analysis by estimating a regression of predicted WFH probabilities against a binary variable capturing whether workers actually worked from home during the pandemic. In the first and fourth columns of Table 6, we present evidence from bivariate regressions in Brazil and Costa Rica, finding that a one standard deviation increase in our measure is associated with an increased likelihood of working from home by 14.1 and 15.8 percentage points, respectively. In fact, this simple regression denotes the strong predictive power of our measure, as the estimated $R^{2}$ equals 0.173 in Brazil and reaches 0.249 in Costa Rica. ${ }^{19,20}$ As such, the predictive power of our WFH measure is closely in line with using worker characteristics and occupations to examine the determinants of WFH outcomes (see columns 2 and 4 in Table 5).

These two validation exercises highlight the usefulness of STEP data for predicting the ability to WFH of different groups (Figures 3 and 4) or even individuals (Table 6). Our predicted

\footnotetext{
${ }^{19}$ We alternatively consider the goodness of fit using a prediction which solely relies on WFH-ability variation at the occupational level. The estimated fit is worse relative to our preferred measure, as the $R^{2}$ for Brazil falls to 0.137 and to 0.218 in Costa Rica.

${ }^{20}$ The remaining columns show these patterns are robust to controlling for worker characteristics and occupations.
} 
Figure 4: Predicted and Actual WFH in Brazil and Costa Rica

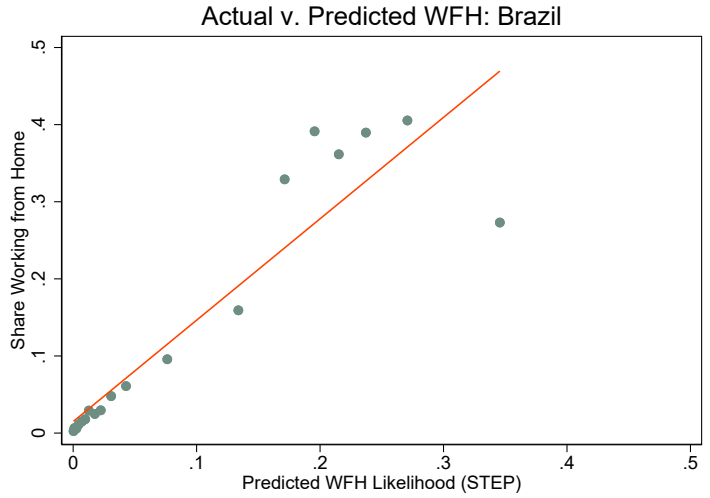

(a) Brazil

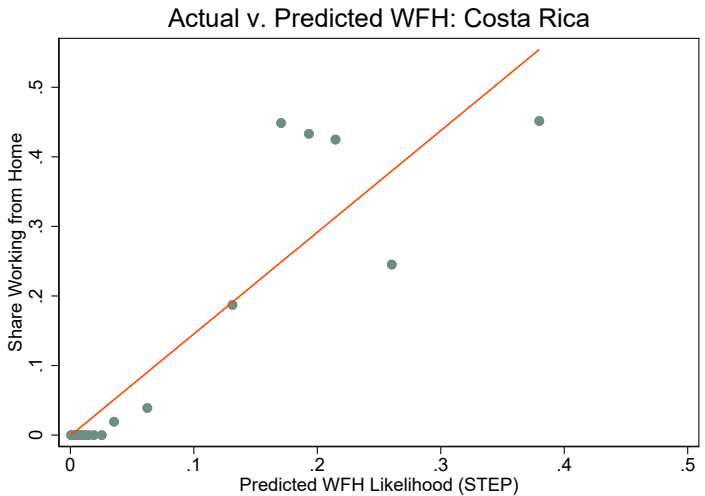

(b) Costa Rica

Source: Skills Towards Employability and Productivity (STEP) Survey, PNAD-COVID19 (Brazil) and Encuesta Continua de Empleo (ECE, Costa Rica). Note: Figure 4 documents the relationship between the prevalence of remote work in Brazil and Costa Rica against the predicted WFH probability from the STEP sample. In STEP, we estimate a probit of the predicted likelihood of WFH including workers' characteristics and their one-digit occupation. We compare the STEP-predicted WFH probability against actual outcomes in two countries by dividing the predicted probabilities in twenty equal-sized groups. We then compare it to the estimated to the share of workers in each bin who are working from home.

WFH probabilities are largely similar in levels to those actually observed in both countries, and are strongly predictive of actual outcomes. This gives us confidence in the transferability of our estimates from STEP to other countries in the same broad income range.

Table 6: Predicted and Observed WFH in Brazil and Costa Rica: Regression Results

\begin{tabular}{|c|c|c|c|c|c|c|}
\hline & \multicolumn{3}{|c|}{ Brazil } & \multicolumn{3}{|c|}{ Costa Rica } \\
\hline & (1) & (2) & (3) & (4) & (5) & (6) \\
\hline WFH-STEP (Standardized) & $\begin{array}{c}0.142^{* * *} \\
(0.001)\end{array}$ & $\begin{array}{c}0.105^{* * *} \\
(0.001)\end{array}$ & $\begin{array}{c}0.171^{* * *} \\
(0.003)\end{array}$ & $\begin{array}{c}0.158^{* * *} \\
(0.008)\end{array}$ & $\begin{array}{c}0.125^{* * *} \\
(0.010)\end{array}$ & $\begin{array}{c}0.083^{* * *} \\
(0.021)\end{array}$ \\
\hline Educational Attainment & & $\begin{array}{c}0.014^{* * *} \\
(0.000)\end{array}$ & $\begin{array}{c}0.003^{* * *} \\
(0.000)\end{array}$ & & $\begin{array}{c}0.009^{* * *} \\
(0.002)\end{array}$ & $\begin{array}{c}-0.003^{* *} \\
(0.001)\end{array}$ \\
\hline Age & & $\begin{array}{r}0.036^{* * *} \\
(0.005)\end{array}$ & $\begin{array}{c}-0.028^{* * *} \\
(0.005)\end{array}$ & & $\begin{array}{c}0.031 \\
(0.031)\end{array}$ & $\begin{array}{l}-0.029 \\
(0.030)\end{array}$ \\
\hline $\mathrm{Age}^{2}$ & & $\begin{array}{l}-0.001 \\
(0.001)\end{array}$ & $\begin{array}{c}0.006^{* * *} \\
(0.001)\end{array}$ & & $\begin{array}{l}-0.002 \\
(0.004)\end{array}$ & $\begin{array}{c}0.004 \\
(0.004)\end{array}$ \\
\hline Male & & $\begin{array}{c}-0.006^{* * *} \\
(0.002)\end{array}$ & $\begin{array}{c}0.007^{* * *} \\
(0.002)\end{array}$ & & $\begin{array}{l}-0.012 \\
(0.010)\end{array}$ & $\begin{array}{l}-0.009 \\
(0.011)\end{array}$ \\
\hline Wage Employment & & $\begin{array}{c}-0.005^{* * *} \\
(0.002) \\
\end{array}$ & $\begin{array}{c}-0.011^{* * *} \\
(0.002)\end{array}$ & & $\begin{array}{c}0.036^{* * * *} \\
(0.006)\end{array}$ & $\begin{array}{c}0.040^{* * * *} \\
(0.008)\end{array}$ \\
\hline Observations & 133,227 & 133,227 & 133,227 & 3,104 & 3,104 & 3,104 \\
\hline$R^{2}$ & 0.174 & 0.196 & 0.250 & 0.250 & 0.259 & 0.349 \\
\hline Occupation FE & None & None & One-Digit & None & None & One-Digit \\
\hline
\end{tabular}

Source: Skills Towards Employability and Productivity (STEP) Survey, PNAD-COVID19 (Brazil) and Encuesta Continua de Empleo (ECE, Costa Rica). Note: Table 6 documents the relationship between the prevalence of remote work in Brazil and Costa Rica against the predicted WFH probability from the STEP sample. The estimated WFH probability follows from a probit model in the STEP sample which includes workers' characteristics and one-digit occupations. We standardize the WFH-STEP measure to be mean zero and variance one, for ease of interpretation. We normalize age by dividing it by ten. Robust standard errors in parentheses. ${ }^{*} p<0.10, * * p<0.05, * * * p<0.01$. 


\section{Predicted WFH and Employment Outcomes}

A natural question which arises is the relationship between WFH ability and employment outcomes during the pandemic. Adams-Prassl et al. (2020a) and Bick et al. (2020) have shown that workers with higher WFH ability are more likely to have remained employed in the US and the UK, yet there is scant evidence on this front in developing countries.

We take advantage of Peru's monthly labor force survey (Encuesta Permanente de Empleo, EPE) which follows a rotating panel design, thus allowing us to observe workers' employment outcomes in their latest pre-Covid survey round. ${ }^{21}$ We focus on individuals who were employed in the 2019 survey wave and examine whether they had a job in the corresponding 2020 survey round. Using their baseline occupation and observed characteristics, we impute a predicted WFH score for each worker from the estimated coefficients from equation (1).

Table 7: Validation Exercise: WFH Score and Employment Outcomes in Peru

\begin{tabular}{|c|c|c|c|}
\hline & 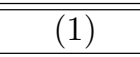 & 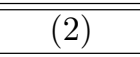 & 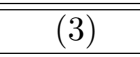 \\
\hline Predicted WFH Ability & $\begin{array}{c}0.381^{* * *} \\
(0.060)\end{array}$ & $\begin{array}{c}0.546^{* * *} \\
(0.097)\end{array}$ & $\begin{array}{r}0.298^{* * *} \\
(0.112)\end{array}$ \\
\hline Industry Essentialness Score & & $\begin{array}{c}0.170^{* * *} \\
(0.022)\end{array}$ & $\begin{array}{c}0.156^{* * *} \\
(0.023)\end{array}$ \\
\hline Interaction: WFH $\times$ Essentialness & & $\begin{array}{c}-0.309^{* *} \\
(0.158)\end{array}$ & $\begin{array}{l}-0.278^{*} \\
(0.161)\end{array}$ \\
\hline Educational Attainment & & & $\begin{array}{c}0.009^{* * *} \\
(0.003)\end{array}$ \\
\hline Age & & & $\begin{array}{c}0.348^{* * *} \\
(0.030)\end{array}$ \\
\hline $\mathrm{Age}^{2}$ & & & $\begin{array}{r}-0.043^{* * *} \\
(0.004)\end{array}$ \\
\hline Male & & & $\begin{array}{c}0.059^{* * *} \\
(0.012)\end{array}$ \\
\hline Wage Employment & & & $\begin{array}{c}0.060^{* * *} \\
(0.013)\end{array}$ \\
\hline Constant & $\begin{array}{c}0.545^{* * *} \\
(0.008)\end{array}$ & $\begin{array}{c}0.467^{* * *} \\
(0.013)\end{array}$ & $\begin{array}{r}-0.317^{* * *} \\
(0.064)\end{array}$ \\
\hline Observations & 7871 & 7871 & 7871 \\
\hline$R^{2}$ & 0.202 & 0.212 & 0.238 \\
\hline
\end{tabular}

Source: Skills Toward Employability and Productivity (STEP) Survey and Encuesta Permanente de Empleo (Peru)

Note: Robust Standard errors in parentheses. ${ }^{*} p<0.10,{ }^{* *} p<0.05$, ${ }^{* * *} p<0.01$. Table 7 presents evidence on the relationship between predicted WFH scores, observed characteristics and the essential nature of sectors on employment outcomes in April-November, 2020 in Peru. The outcome variable is a binary variable capturing whether workers remained employed in 2020. WFH scores are predicted using the estimated coefficients from a modified version of equation (1) (without country fixed effects). The second row refers to the industry essentialness score from Gottlieb et al. (2021). The third row shows the interaction between the WFH score and the share of employment in the sector carried out.

The first column of Table 7 shows that a higher WFH score is strongly associated with the likelihood of remaining employed through 2020 in Peru. We further examine the extent to which this relationship varies across the essential nature of the sector in which Peruvian workers were

\footnotetext{
${ }^{21}$ We focus our analysis on Peru, as the employment surveys in Brazil and Costa Rica do not follow a panel design. Conversely, no measures of actual WFH are available in the Peruvian EPE.
} 
employed in 2019, as we expect that WFH ability should be a stronger predictor of employment in non-essential industries. ${ }^{22}$ The second and third columns show that the WFH score strongly predicts the likelihood of keeping a job through 2020 in non-essential sectors, and the relationship is far weaker in less essential industries. In light of these results, we conclude that our measure is a good predictor not only of actual WFH, but also of employment outcomes in developing countries throughout the pandemic.

\section{Conclusion}

In this paper, we propose a measure of the ability to WFH for developing countries, using information on job task content from a worker-level survey. Our measure indicates that fewer than $10 \%$ of urban jobs in developing countries can be done remotely. Various vulnerable groups are less likely to work remotely, including workers in low-wage occupations, high school dropouts and self-employed individuals. Importantly, our results indicate that the low WFH ability in developing countries is driven not only by occupational composition but also by the nature of tasks within occupations.

In the second part of the paper, we take advantage of recent data from Brazil, Costa Rica and Peru on actual WFH and employment outcomes during the pandemic. We show that actual WFH in the second quarter of 2020 was in line with our predicted WFH ability measure. Moreover, we document substantial heterogeneity in the types of workers who have actually worked from home. Also, we show that WFH ability is strongly correlated with the likelihood of staying employed during the pandemic.

The measure of the ability to WFH that we propose in this paper can be used to predict work WFH in developing countries. Table 1 and Table A2 provide a measure of the ability to WFH for various subgroups of the work force. As a result, we remark that it is possible to calculate WFH ability for a broad range of developing countries if weighted by the employment shares of these subgroups.

Our paper provides valuable information on the groups of the work force that are hit hardest by policies that aim at taming the spread of the pandemic, and should prove useful to the quantitative analysis of the effects of social distancing, including the study of optimal policies.

\section{References}

Adams-Prassl, A., T. Boneva, M. Golin, and C. Rauh (2020a). Inequality in the impact of the coronavirus shock: Evidence from real time surveys. Journal of Public Economics 189, 104245.

\footnotetext{
${ }^{22}$ We measure the essential nature of a sector using a variable constructed by Gottlieb et al. (2021), which relies on an index assembled by Fana et al. (2020) documenting activities exempt from the strict March 2020 lockdown decrees in Germany, Italy, and Spain. In particular, we consider the share of one-digit industry-level employment which was carried out in these countries during the pandemic to capture the essential nature of different sectors.
} 
Adams-Prassl, A., T. Boneva, M. Golin, and C. Rauh (2020b, May). Work Tasks That Can Be Done From Home: Evidence on the Variation Within and Across Occupations and Industries. Cambridge Working Papers in Economics 2040, Faculty of Economics, University of Cambridge.

Alipour, J.-V., O. Falck, and S. Schller (2020, April). Germany's Capacities to Work from Home. IZA Discussion Papers 13152, Institute of Labor Economics (IZA).

Andrew, A., S. Cattan, M. Costa Dias, C. Farquharson, L. Kraftman, S. Krutikova, A. Phimister, and A. Sevilla (2020, July). The Gendered Division of Paid and Domestic Work under Lockdown. IZA Discussion Papers 13500, Institute of Labor Economics (IZA).

Autor, D. H. and M. J. Handel (2013). Putting tasks to the test: Human capital, job tasks, and wages. Journal of Labor Economics 31(S1), S59-S96.

Belot, M., S. Choi, E. Tripodi, E. van den Broek-Altenburg, J. C. Jamison, and N. W. Papageorge (2020, June). Unequal Consequences of COVID-19 across Age and Income: Representative Evidence from Six Countries. IZA Discussion Papers 13366, Institute of Labor Economics (IZA).

Bick, A., A. Blandin, and K. Mertens (2020, July). Work from Home After the COVID-19 Outbreak. CEPR Discussion Papers 15000, C.E.P.R. Discussion Papers.

Boeri, T., A. Caiumi, and M. Paccagnella (2020). Mitigating the work-security trade-off while rebooting the economy. Covid Economics 2.

del Rio-Chanona, R. M., P. Mealy, A. Pichler, F. Lafond, and D. Farmer (2020). Supply and demand shocks in the covid-19 pandemic: An industry and occupation perspective. Covid Economics 6.

Dicarlo, E., S. L. Bello, S. Monroy-Taborda, A. M. Oviedo, M. L. Sanchez-Puerta, and I. Santos (2016). The Skill Content of Occupations Across Low and Middle Income Countries: Evidence from Harmonized Data. IZA Discussion Papers 10224, Institute of Labor Economics (IZA).

Dingel, J. I. and B. Neiman (2020). How many jobs can be done at home? Journal of Public Economics 189, 104235.

Eurofound (2020). Living, working and Covid-19. COVID-19 series.

Fadinger, H., J. Schymik, et al. (2020). The effects of working from home on Covid-19 infections and production a macroeconomic analysis for germany. Covid Economics 9.

Fana, M., S. Tolan, S. Torrejón, C. Urzi Brancati, and E. Fernández-Macías (2020). The covid confinement measures and eu labour markets. Publications Office of the European Union.

Farr, L., Y. Fawaz, L. Gonzalez, and J. Graves (2020, July). How the COVID-19 Lockdown Affected Gender Inequality in Paid and Unpaid Work in Spain. IZA Discussion Papers 13434, Institute of Labor Economics (IZA). 
Garrote Sanchez, D., N. Gomez Parra, C. Ozden, B. Rijkers, M. Viollaz, and H. J. Winkler (2020, July). Who on Earth Can Work from Home ? Policy Research Working Paper Series 9347, The World Bank.

Gottlieb, C., J. Grobovšek, and M. Poschke (2020). Working from home across countries. Covid Economics 7.

Gottlieb, C., J. Grobovšek, M. Poschke, and F. Saltiel (2021). Lockdown accounting. The B.E. Journal of Macroeconomics.

Hale, T., S. Webster, A. Petherick, T. Phillips, and B. Kira (2020). Oxford Covid-19 government response tracker. Blavatnik School of Government 25.

Handel, M. J. (2016). The O*NET content model: Strengths and limitations. Journal for Labour Market Research 49(2), 157-176.

Hatayama, M., M. Viollaz, and H. Winkler (2020). Jobs' amenability to working from home: Evidence from skills surveys for 53 countries. World Bank Policy Research Working Paper (9241).

Hensvik, L., T. Le Barbanchon, and R. Rathelot (2020, April). Which Jobs Are Done from Home? Evidence from the American Time Use Survey. IZA Discussion Papers 13138, Institute of Labor Economics (IZA).

Lewandowski, P., A. Park, W. Hardy, and Y. Du (2019, May). Technology, Skills, and Globalization: Explaining International Differences in Routine and Nonroutine Work Using Survey Data. IZA Discussion Papers 12339, Institute of Labor Economics (IZA).

Lo Bello, S., M. L. Sanchez Puerta, and H. Winkler (2019, March). From Ghana to America: The Skill Content of Jobs and Economic Development. IZA Discussion Papers 12259, Institute of Labor Economics (IZA).

Mongey, S., L. Pilossoph, and A. Weinberg (2020, May). Which Workers Bear the Burden of Social Distancing Policies? NBER Working Papers 27085, National Bureau of Economic Research, Inc.

Saltiel, F. (2019). Comparative Evidence on the Returns of Tasks in Developing Countries. mimeo.

Saltiel, F. (2020). Who can work from home in developing countries. Covid Economics 7, 104-118.

Stinebrickner, R., T. Stinebrickner, and P. Sullivan (2019). Job Tasks, Time Allocation, and Wages. Journal of Labor Economics 37(2), 399-433. 


\section{Appendices}

\section{A Appendix Tables and Figures}

Table A1: Share of WFH Ability by One-Digit Occupation and Country

\begin{tabular}{lccccccccccc}
\hline & $\begin{array}{c}\text { All } \\
(1)\end{array}$ & $\begin{array}{c}\text { Armenia } \\
(2)\end{array}$ & $\begin{array}{c}\text { Bolivia } \\
(3)\end{array}$ & $\begin{array}{c}\text { China } \\
(4)\end{array}$ & $\begin{array}{c}\text { Colombia } \\
(5)\end{array}$ & $\begin{array}{c}\text { Georgia } \\
(6)\end{array}$ & $\begin{array}{c}\text { Ghana } \\
(7)\end{array}$ & $\begin{array}{c}\text { Kenya } \\
(8)\end{array}$ & $\begin{array}{c}\text { Laos } \\
(9)\end{array}$ & $\begin{array}{c}\text { Macedonia } \\
(10)\end{array}$ & $\begin{array}{c}\text { Vietnam } \\
(11)\end{array}$ \\
\hline \hline Sample Average & 0.093 & 0.104 & 0.060 & 0.143 & 0.058 & 0.154 & 0.032 & 0.074 & 0.033 & 0.123 & 0.141 \\
\hline Manager & 0.238 & 0.311 & 0.102 & 0.156 & 0.161 & 0.312 & 0.186 & 0.225 & 0.187 & 0.263 & 0.419 \\
Professional & 0.196 & 0.116 & 0.117 & 0.223 & 0.234 & 0.184 & 0.136 & 0.24 & 0.115 & 0.232 & 0.391 \\
Technician & 0.2 & 0.14 & 0.17 & 0.243 & 0.103 & 0.244 & 0.148 & 0.293 & 0.178 & 0.174 & 0.345 \\
Clerical & 0.282 & 0.304 & 0.199 & 0.332 & 0.21 & 0.37 & 0.119 & 0.309 & 0.237 & 0.218 & 0.315 \\
Services/Sales & 0.03 & 0.027 & 0.035 & 0.058 & 0.031 & 0.076 & 0.005 & 0.012 & 0.003 & 0.044 & 0.044 \\
Agricultural & 0.001 & 0 & 0.05 & 0 & 0 & 0 & 0 & 0 & 0 & 0 & 0 \\
Craft/Trades & 0.012 & 0.01 & 0.007 & 0.027 & 0.009 & 0.018 & 0.011 & 0.014 & 0 & 0.014 & 0.016 \\
Machine Operators & 0.007 & 0.024 & 0.009 & 0.023 & 0 & 0 & 0 & 0 & 0 & 0.004 & 0.005 \\
Elementary Occupations & 0.013 & 0.006 & 0.01 & 0.064 & 0.005 & 0.017 & 0.005 & 0.002 & 0 & 0.021 & 0.011 \\
\hline \hline
\end{tabular}

Source: Skills Toward Employability and Productivity (STEP) Survey. Note: Table A1 presents evidence on the share of workers who can work from home by one-digit occupation and country. Results are weighted using sample weights to represent the working-age population of 15 -64 year olds.

Table A2: WFH Ability by Occupations and Characteristics in STEP

\begin{tabular}{lcccccccccc}
\hline Gender & & \multicolumn{4}{c}{ Males } & \multicolumn{4}{c}{ Females } \\
Education & \multicolumn{4}{c}{ HS Graduate } & \multicolumn{4}{c}{ HS Dropout } & \multicolumn{3}{c}{ HS Graduate } & HS Dropout \\
Self-Employment & Full Sample & Wage & Self & Wage & Self & Wage & Self & Wage & Self \\
One-Digit Occupation & $(1)$ & $(2)$ & $(3)$ & $(4)$ & $(5)$ & $(6)$ & $(7)$ & $(8)$ & $(9)$ \\
\hline Managers & 0.238 & 0.308 & 0.166 & 0.173 & 0.115 & 0.311 & 0.211 & 0.061 & 0.042 \\
Professionals & 0.196 & 0.216 & 0.179 & 0.020 & 0.164 & 0.201 & 0.125 & 0.108 & 0.123 \\
Technicians and Associate Professionals & 0.200 & 0.231 & 0.091 & 0.113 & 0.036 & 0.231 & 0.228 & 0.074 & 0.000 \\
Clerical Support Workers & 0.282 & 0.218 & 0.337 & 0.134 & 0.105 & 0.372 & 0.192 & 0.138 & 0.000 \\
Services and Sales Workers & 0.030 & 0.054 & 0.047 & 0.017 & 0.015 & 0.076 & 0.031 & 0.012 & 0.004 \\
Skilled Agricultural, Forestry and Fishery Workers & 0.001 & 0.007 & 0.006 & 0.000 & 0.000 & 0.000 & 0.000 & 0.000 & 0.000 \\
Craft and Related Trades Workers & 0.012 & 0.014 & 0.039 & 0.004 & 0.006 & 0.034 & 0.014 & 0.000 & 0.004 \\
Plant and Machine Operators, and Assemblers & 0.007 & 0.017 & 0.008 & 0.000 & 0.000 & 0.014 & 0.000 & 0.000 & 0.000 \\
Elementary Occupations & 0.013 & 0.029 & 0.000 & 0.001 & 0.000 & 0.049 & 0.082 & 0.001 & 0.006 \\
\hline Sample Average & 0.093 & 0.143 & 0.081 & 0.019 & 0.014 & 0.191 & 0.067 & 0.022 & 0.005 \\
\hline Observations & 17592 & 3599 & 1299 & 1923 & 1422 & 3915 & 1277 & 1658 & 2499 \\
\hline
\end{tabular}

Source: Skills Toward Employability and Productivity (STEP) Survey. Note: Table A2 documents the share of workers who can work from home by 72 categories encompassing one-digit occupation, educational attainment, self-employment and gender. Results are weighted using sample weights to represent the working-age population of 15-64 year olds in each STEP country. 
Table A3: Work from Home Ability by Definition and Two-Digit ISCO Occupation

\begin{tabular}{|c|c|c|}
\hline Occupation name (ISCO 2) & WFH employment, STEP & WFH employment, Dingel and Niemann \\
\hline Chief Executives, Senior Officials and Legislators & 0.28 & 0.66 \\
\hline Administrative and Commercial Managers & 0.25 & 0.89 \\
\hline Production and Specialized Services Managers & 0.25 & 0.67 \\
\hline Hospitality, Retail and Other Services Managers & 0.20 & 0.13 \\
\hline Science and Engineering Professionals & 0.30 & 0.67 \\
\hline Health Professionals & 0.09 & 0.12 \\
\hline Teaching Professionals & 0.09 & 0.96 \\
\hline Business and Administration Professionals & 0.42 & 0.94 \\
\hline Information and Communications Technology Professionals & 0.29 & 1.00 \\
\hline Legal, Social and Cultural Professionals & 0.24 & 0.68 \\
\hline Science and Engineering Associate Professionals & 0.16 & 0.16 \\
\hline Health Associate Professionals & 0.06 & 0.04 \\
\hline Business and Administration Associate Professionals & 0.29 & 0.70 \\
\hline Legal, Social, Cultural and Related Associate Professionals & 0.16 & 0.56 \\
\hline Information and Communications Technicians & 0.26 & 0.84 \\
\hline General and Keyboard Clerks & 0.34 & 1.00 \\
\hline Customer Services Clerks & 0.25 & 0.31 \\
\hline Numerical and Material Recording Clerks & 0.27 & 0.55 \\
\hline Other Clerical Support Workers & 0.22 & 0.65 \\
\hline Personal Services Workers & 0.03 & 0.17 \\
\hline Sales Workers & 0.03 & 0.17 \\
\hline Personal Care Workers & 0.04 & 0.18 \\
\hline Protective Services Workers & 0.04 & 0.10 \\
\hline Market-oriented Skilled Agricultural Workers & 0.00 & 0.04 \\
\hline Market-oriented Skilled Forestry, Fishery and Hunting Workers & 0.00 & 0.03 \\
\hline Subsistence Farmers, Fishers, Hunters and Gatherers & 0.00 & 0.00 \\
\hline Building and Related Trades Workers (excluding electricians) & 0.02 & 0.01 \\
\hline Metal, Machinery and Related Trades Workers & 0.01 & 0.00 \\
\hline Handicraft and Printing Workers & 0.04 & 0.25 \\
\hline Electrical and Electronics Trades Workers & 0.01 & 0.00 \\
\hline Food Processing, Woodworking, Garment and Other Craft and Related Trades Workers & 0.00 & 0.11 \\
\hline Stationary Plant and Machine Operators & 0.01 & 0.00 \\
\hline Assemblers & 0.00 & 0.00 \\
\hline Drivers and Mobile Plant Operators & 0.01 & 0.01 \\
\hline Cleaners and Helpers & 0.00 & 0.00 \\
\hline Agricultural, Forestry and Fishery Labourers & 0.01 & 0.00 \\
\hline Labourers in Mining, Construction, Manufacturing and Transport & 0.01 & 0.03 \\
\hline Food Preparation Assistants & 0.00 & 0.00 \\
\hline Street and Related Sales and Services Workers & 0.07 & 0.00 \\
\hline Refuse Workers and Other Elementary Workers & 0.02 & 0.19 \\
\hline
\end{tabular}

Note: Table A3 compares the estimated WFH shares at the two-digit occupation level using different measures. Column 1 reports the share of WFH employment at the ISCO-2 occupation-level using the measure outlined in section 2.2 based on STEP data. Column 2 reports the share of WFH employment as measured by Dingel and Neiman (2020) based on O*NET data. 
Figure A1: Mobility Trends for Workplaces in Brazil, Costa Rica and the US

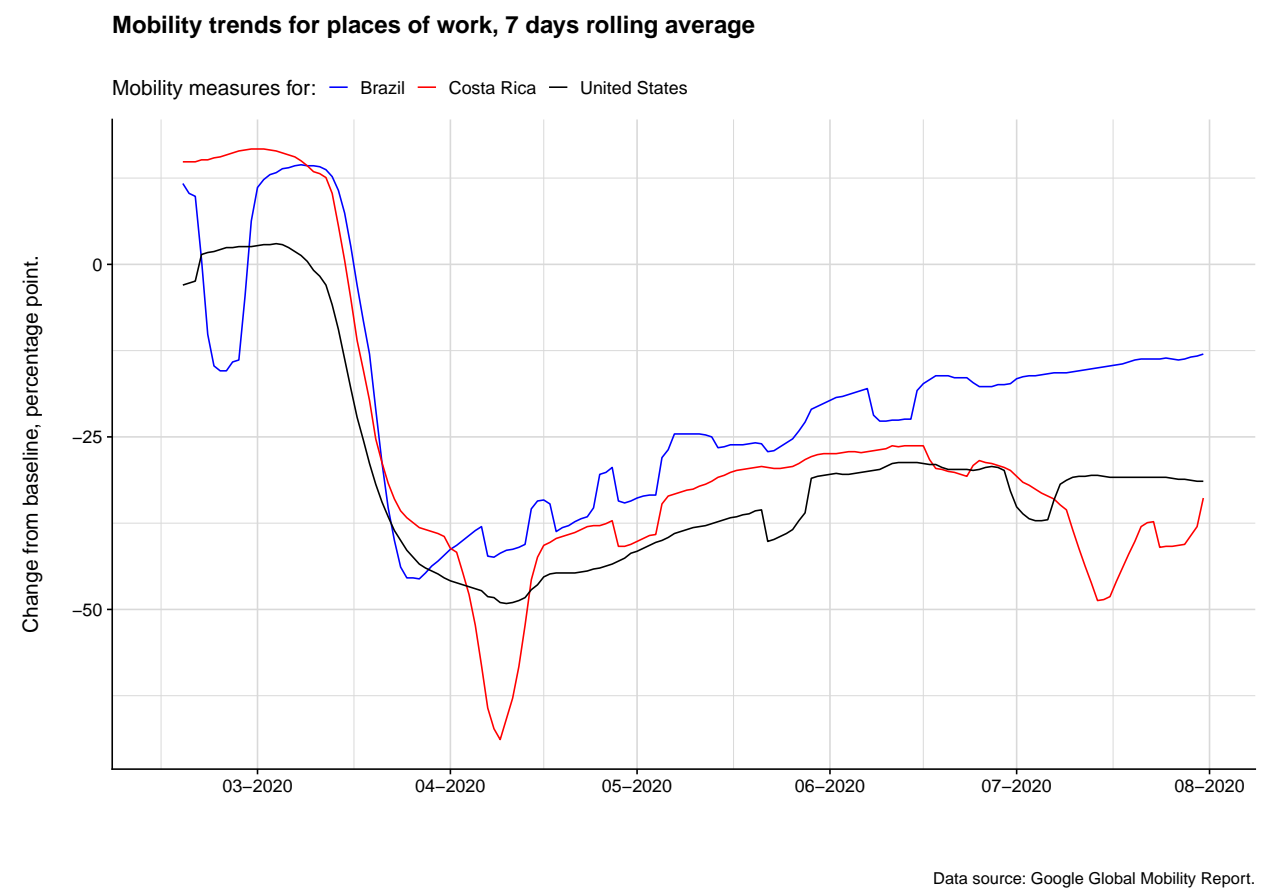

Note: Figure A1 documents the extent of changes in individuals' work-based mobility in Brazil, Costa Rica and the United States from March, 2020 through August, 2020. 
Figure A2: WFH Ability Across Countries

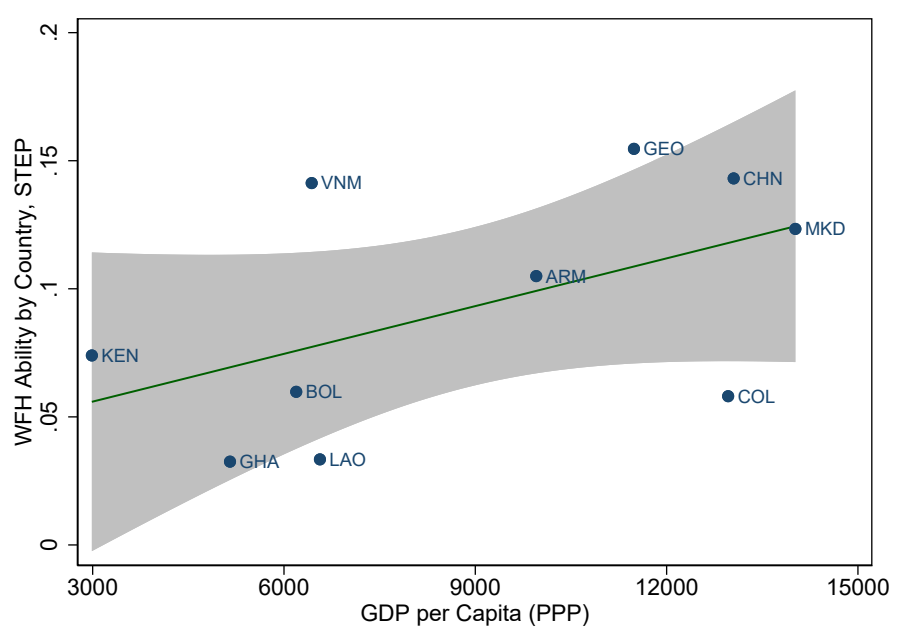

Source: Skills Toward Employability and Productivity (STEP). Note: Figure A2 presents the estimated share of jobs which can be done from home across countries in the STEP sample.

Figure A3: Comparison of Estimated WFH Ability to Dingel and Neiman (2020)

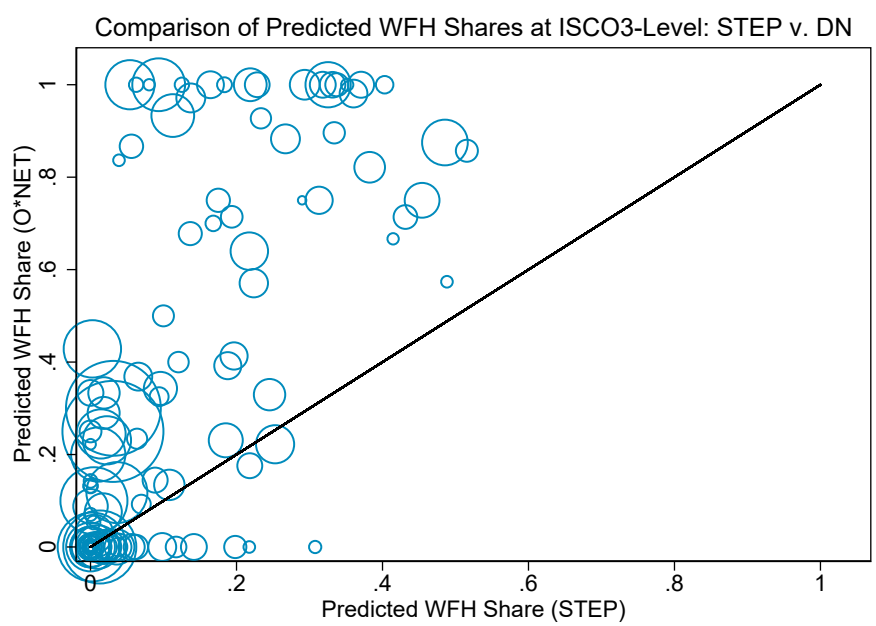

Source: Skills Toward Employability and Productivity (STEP). Note: Figure A3 presents the share of jobs which can be done from home at the three-digit occupation level following the measure introduced in Section 2.2. We compare the estimated WFH share to Dingel and Neiman (2020). We restrict the analysis to three-digit occupations with at least ten respondents in STEP. Results are weighted using STEP sample weights to represent the working-age population of 15-64 year olds. 
Figure A4: Prevalence of WFH in Costa Rica by Education, 2011-2020

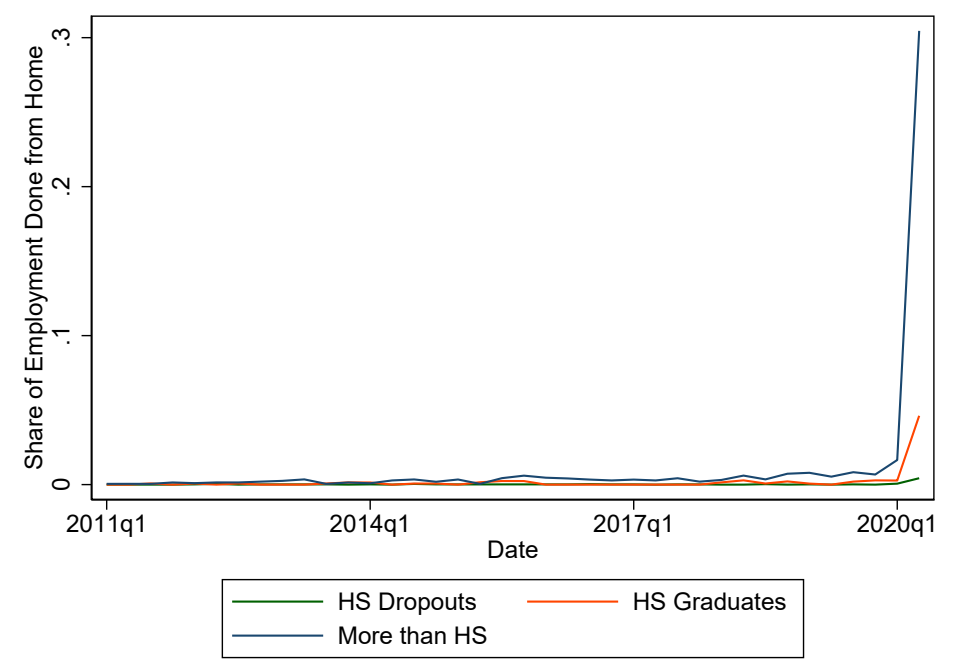

Source: Encuesta Continua de Empleo (ECE in Costa Rica). Note: Figure A4 documents the extent of telework in Costa Rica between 2011 and 2020 by workers' educational attainment, covering high school dropouts, high school graduates and those who went beyond high school. 


\section{B Data Appendix}

STEP Data. We take advantage of data from the 2012-2013 survey rounds in the Skills Toward Employment and Productivity (STEP) household survey, covering information for urban workers in Armenia, Bolivia, China. Colombia, Georgia, Ghana, Kenya, Laos, Macedonia and Vietnam. We use information on the main respondents' labor market outcomes and impose various restrictions to the baseline surveys. We first focus on workers who were employed at some point in the twelve months prior to the survey, which reduces the original sample from 30,195 to 19,370 workers. Furthermore, we restrict the sample to individuals who were either self-employed or who worked as employees, thus removing those in unpaid family work. Since our analysis requires information on occupational outcomes, we drop workers with missing occupation codes and those in military occupations. We similarly drop workers with missing task information and those who do not report the observed characteristics we use for our empirical analysis. While STEP surveys focused on urban workers, some rural-based workers were surveyed in a number of countries. We further restrict the sample to urban workers for comparability, resulting in our final sample of 17,592 workers across the ten counties in STEP. We lastly note that our analysis encompassing the entire STEP sample applies weights to represent the working-age population of 15-64 year olds in each country, such that countries are weighted equally.

Table B1: Work from Home Measurement: STEP v. O*NET

\begin{tabular}{|c|c|c|}
\hline Questionnaire & STEP & O*NET \\
\hline Section & Skills at work & Work context \\
\hline 1 & $\begin{array}{l}\text { Do you regularly have to lift or pull any- } \\
\text { thing weighing at least } 25 \text { kilos? Binary } \\
\text { response. }\end{array}$ & $\begin{array}{l}\text { Performing General Physical Activities is } \\
\text { very important }(4.0+\text { of } 5)\end{array}$ \\
\hline 2 & $\begin{array}{l}\text { As part of this work, do you (did you) re- } \\
\text { pair/maintain electronic equipment? Bi- } \\
\text { nary response. }\end{array}$ & $\begin{array}{l}\text { Repairing and Maintaining Electronic } \\
\text { Equipment is very important }(4.0+\text { of } 5)\end{array}$ \\
\hline 3 & $\begin{array}{l}\text { As part of this work, do you (did you) op- } \\
\text { erate or work with any heavy machines or } \\
\text { industrial equipment? }\end{array}$ & $\begin{array}{l}\text { Operating Vehicles, Mechanized Devices, } \\
\text { or Equipment is very important }(4.0+\text { of } \\
5)\end{array}$ \\
\hline 4 & $\begin{array}{l}\text { Time involved with customers. Ranked on } \\
\text { a scale from 1-10 only for workers who } \\
\text { answered positively to "Do you contact } \\
\text { non-coworkers?" Deemed important if re- } \\
\text { sponded with a } 9 \text { or } 10 \text {. }\end{array}$ & $\begin{array}{l}\text { Performing for or Working Directly with } \\
\text { the Public is very important }(4.0+\text { of } 5)\end{array}$ \\
\hline Section & Generalized work activities & \\
\hline 5 & $\begin{array}{l}\text { Does your work require the use of the fol- } \\
\text { lowing [e-mail]? Binary response. }\end{array}$ & $\begin{array}{l}\text { "Average respondent says they use email } \\
\text { less than once per month" }\end{array}$ \\
\hline
\end{tabular}

